\title{
Adsorption Properties and Potential Applications of Bamboo Charcoal: A Review
}

\author{
S.S.M. Isa ${ }^{1,{ }^{*}}$, M.M. Ramli ${ }^{1}$, N.A.M.A. Hambali ${ }^{1}$, S.R. Kasjoo ${ }^{1}$, M.M. Isa ${ }^{1}$, N.I.M. Nor ${ }^{1}$, N. \\ Khalid $^{1}$, and N. Ahmad ${ }^{1}$ \\ ${ }^{1}$ School of Microelectronic Engineering, Universiti Malaysia Perlis, Pauh Putra Campus, 02600 Arau, \\ Perlis, Malaysia
}

\begin{abstract}
Bamboo charcoal was produced by pyrolysis or carbonization process with extraordinary properties such as high conductivity, large surface area and adsorption property. These properties can be improved by activation process that can be done thermally or chemically. In this paper, carbonization and activation process of bamboo, its structural and adsorption properties will be presented. Herein, the adsorption properties of bamboo charcoal that has fully utilized in solar cell as the electrode, adsorbent for water purification and electromagnetic wave absorber are reviewed.
\end{abstract}

\section{Introduction}

Bamboo charcoal is made up from pieces of bamboo ( 5 years $>$ ) which undergoes a heat treatment normally at $800-1200{ }^{\circ} \mathrm{C}$ (pyrolysis process). As early as $1486 \mathrm{AD}$, bamboo charcoal has been used in various ways due to its tremendous extraordinary properties. What makes this charcoal is so amazing is the carbonization process which creates a product with an enormous surface area to mass ratio which has high ability to attract and hold (adsorption) a wide range of materials, chemicals, minerals, radiowaves, humidity, odours and harmful substances.

Among all, absorption property of this material is well discussed and has been utilized in various applications such as household products (water filtration, humidity and odour adsorbent, air freshener, fruits and vegetables saver etc.) and health and beauty products (soap, powder, foot patch etc.). After carbonized, this material can be used as an efficient absorbent. Depends on what it adsorbs, the carbonized bamboo also can become saturated and act as the fertilizer. In another hand, the adsorbed impurities can be burned off without destroying the adsorbent property, which means it can be reused. The adsorption properties of bamboo charcoal can be improved and become a perfect absorbent when this material is further activated either thermally or chemically. No longer limited to the previous applications, recently, the bamboo charcoal has been applied as the working electrode composite in dye sensitized solar cell to increase device efficiency [1], as the absorbent for water purification [2] and microwave absorber in antenna [3].

\footnotetext{
* Corresponding author: sitisalwa@unimap.edu.my
} 
Become the alternative to activated carbon, carbon nanotubes, graphene and other carbon based materials, this element is the most notable among readily and renewable biomass resources because bamboo is the fastest growing plants in Earth [4]. In this study, bamboo charcoal production, structural and adsorption properties specifically in dye sensitized solar cell, water purification and microwave absorber are reviewed.

\section{Carbonization of camboo charcoal}

Generally, Moso bamboo (Phyllostachys pubenscens) is used as the starting material in the production. This bamboo is cut into small pieces and washed by boiling distilled water for some hours and dried at temperature nearly $110{ }^{\circ} \mathrm{C}$ to remove moisture [5]. Then, the carbonization process is held in the oven normally at $\mathrm{N}_{2}$ flow [2] at temperature over 800$1200{ }^{\circ} \mathrm{C}$ at longer period hours. However, bamboo charcoal also can be produced at lower temperature $\left(500-900{ }^{\circ} \mathrm{C}\right)$ with different quality which has been presented in [2]. The fresh bamboo charcoal produced from this process is the raw bamboo charcoal. This material already has an extraordinary micro structure with high absorptive capacity.
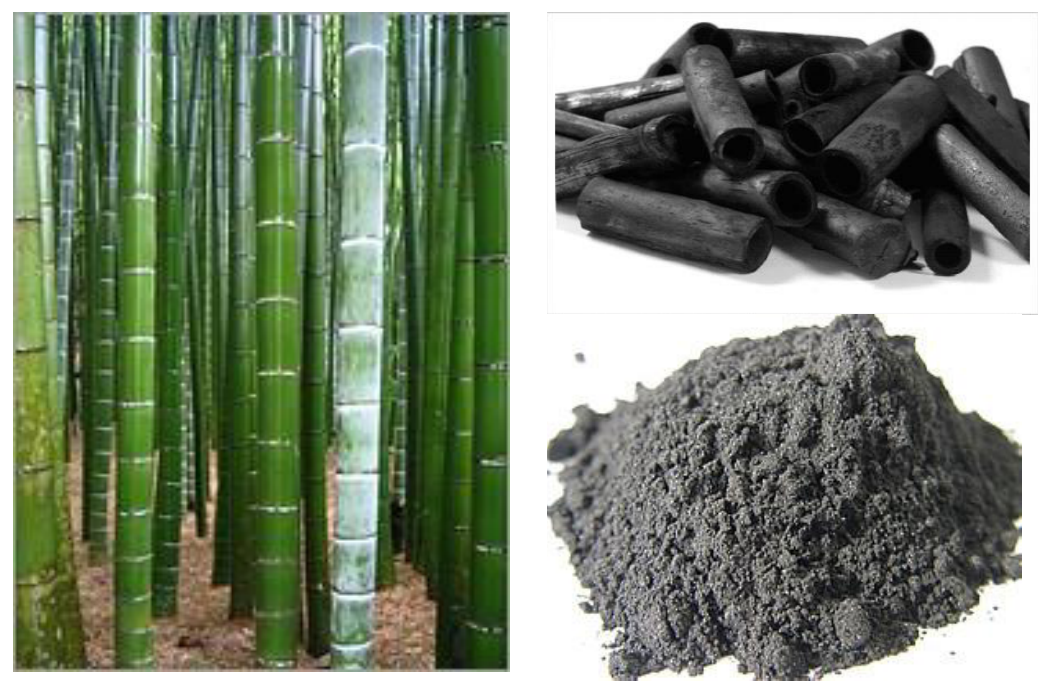

Fig. 1. Bamboo (a) Moso, (b) charcoal and (c) powder.

\section{Activation of bamboo charcoal}

Activation of carbonized bamboo charcoal is important to improve the original structure and increase the adsorption properties. It can be mixed with $\mathrm{CO}_{2}[2,6], \mathrm{HNO}_{3}$ [2,7], $\mathrm{NH}_{3}$ $[2,8]$ and many more before it is heated again at certain temperature $\left(500-1200{ }^{\circ} \mathrm{C}\right)$ for some periods. The annealed bamboo charcoal need to be cooled to a temperature between 170 to $240{ }^{\circ} \mathrm{C}$ before it serves as activated bamboo charcoal. The activation step is important to increase the volume of the material, breaks some bonds of the turbostratic carbon structures that form surface functional groups and removes non-crystallized carbons from the bamboo charcoals. 


\section{Structure and adsorption properties}

Figure 2 shows the structure of bamboo charcoal before and after activation. As shown in the figures, vascular bundles of the bamboo charcoal are arranged in various sizes. The pore characteristics of this material can be macropore $(>50 \mathrm{~nm})$, mesopore $(2-50 \mathrm{~nm})$ or micropore $(<2 \mathrm{~nm})$. This pore characteristic and the resistant coefficient of this material are affected by the temperature of carbonization and activation processes. As the temperature increases, the material will change from insulator to semiconductor or even to conductor, while the pore size is getting bigger. Normal and activated bamboo charcoal have the same ability to absorb chemicals and substances from air and water, however the normal bamboo charcoal has poor holding capacity compared to the activated forms. Other than surface area to mass ratio, the excellent adsorption property is contributed by the van der Waals force [11].

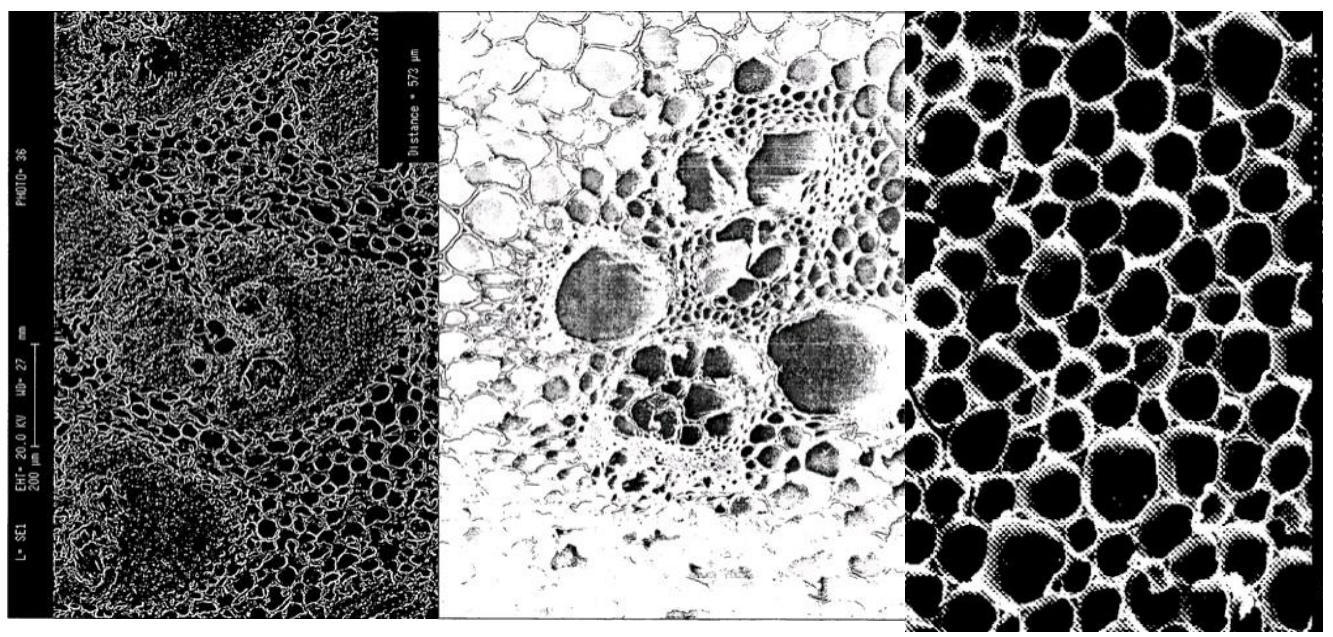

Fig. 2. Bamboo charcoal structure (a) after carbonization, (b) after activation [9] and (c) at higher magnification [10].

\section{As electrodes in dye sensitized solar cell}

Conventionally in Dye Sensitized Solar Cell (DSSC), carbon based material and titanium dioxide $\left(\mathrm{TiO}_{2}\right)$ were employed as counter and working electrodes. However, $\mathrm{TiO}_{2}$ working electrodecan only absorb ultraviolet and several approaches including the use of dopants such as nitrogen [12], hydrogen [13], metal [14] and others to introduce disorder in the surface layer and narrow the band gap of $\mathrm{TiO}_{2}$ which can improve the photocatalytic activities were done. The introduction of disorder and dopant at the surface would enhance visible and infrared absorption [13]. Several initiatives using carbonaceous materials such as graphene [15], carbon nanotubes [16] and hybrid graphene-carbon nanotubes [17] have been performed in order to increase device efficiency due to their good conductivity and high effective surface area. These materials can help the electron excitation and enhance the light harvest efficiency of the photoanode and working electrode when hybridizing this material with $\mathrm{TiO}_{2}$.

Aside from the stated carbon based materials, mesoporous carbon such as bamboo charcoal also potentials to be used as the electrodes in DSSC. Carbonized bamboo charcoal which undergoes heat treatment between 700 to $900{ }^{\circ} \mathrm{C}$ has the resistance 
coefficient between 0.12 to $11.9 \Omega \mathrm{m}$ which perfect as the electrode [10]. In other work, Chen et al. [13] has proved that modified $\mathrm{TiO}_{2}$ potentials to increase solar absorption by altering the surface structure and its energy band. The black $\mathrm{TiO}_{2}$ (refer Fig. 3(a)) can be resolved into two peaks compared to typical white $\mathrm{TiO}_{2}$. The changes in reflectance and absorbance spectra at $806.8 \mathrm{~nm}$ suggest that the optical gap of the black $\mathrm{TiO}_{2}$ was narrowed by intraband transition. Further analysis with XPS (Fig. 3(b)) also has been performed to show the changes of density of states between typical $\mathrm{TiO}_{2}$ and modified $\mathrm{TiO}_{2}$ and the results were illustrated in Fig. 3(c).

Recently, the best performance of bamboo charcoal in DSSC is 5.4\% [1] attributed to the porous of bamboo charcoal embedded in the nano-crystalline $\mathrm{TiO}_{2}$ which facilitates the capability of dye absorption and the generation of electrons during exposure to the light. However, the development of DSSC utilizing bamboo charcoal still in preliminary stage and more improvements need to be done.
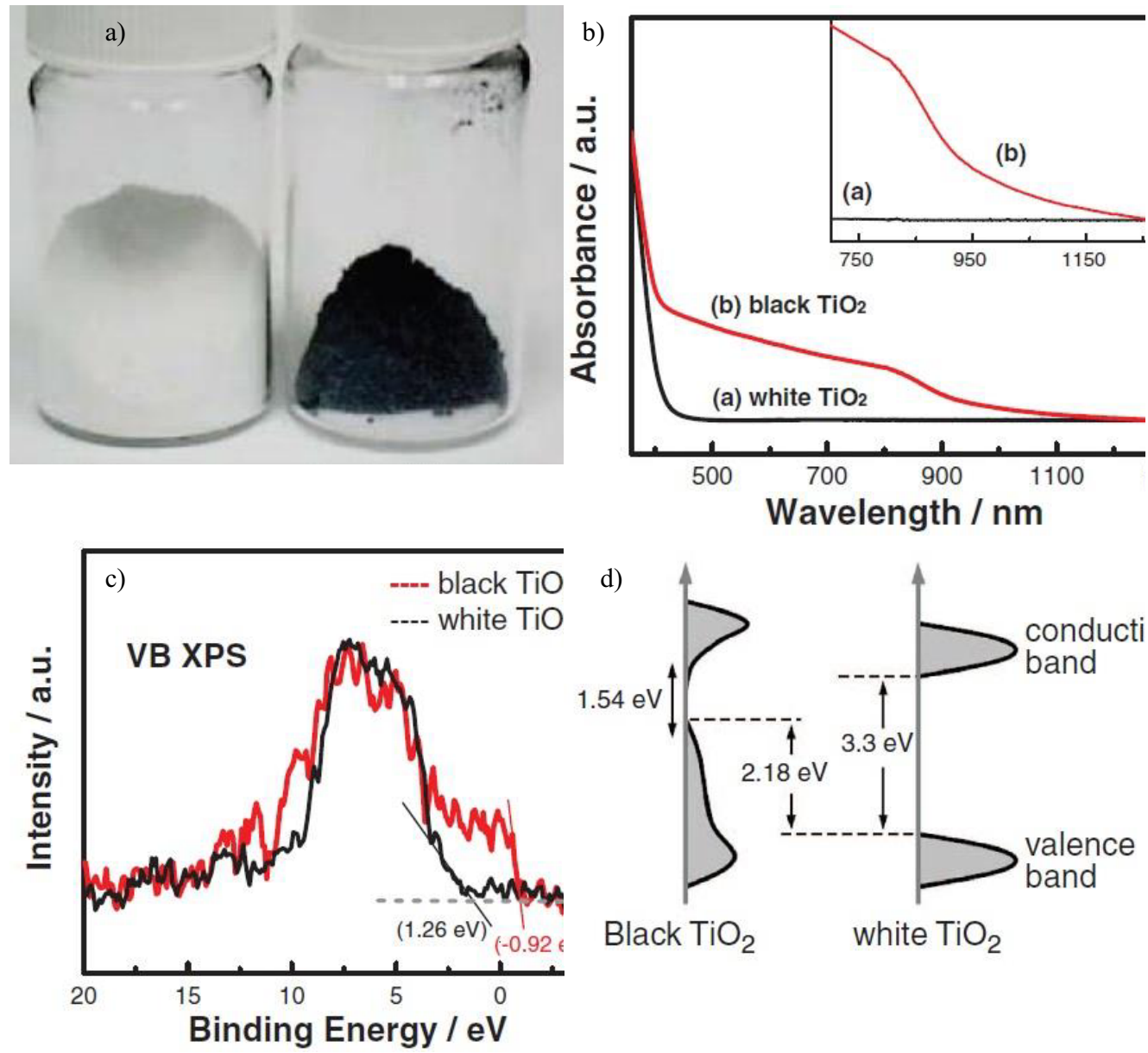

Fig. 3. Comparison between typical $\mathrm{TiO}_{2}$ and modified (a) powder forms, (b) Spectral absorbance, (c) XPS spectra and (d) Illustration of density of states [13]. 


\section{As an absorbent in water purification}

Many industries produce volatile compounds that can pollute the environment and harm the human health. The common compounds include hydrocarbon compounds such as $\mathrm{O}_{2}$, $\mathrm{N}_{2}$, sulphur, halogen and others. Generally, adsorbents were employed to remove the pollutants from wastewater or waste gas. The adsorption capacity of the adsorbents comes from the affinity of molecules, and is classified into physical adsorption, chemical adsorption and catalytic action. Examples of adsorbent are activated clays, aluminium oxide based materials, silica gel, ion exchangers, magnesia based materials, activated carbon and others. Among all, the activated carbon is the most common used absorbent as it is cheaper, easier to be used and recyclable. It has superior performance in dealing with organic and toxic waste such as chrome, ozone, pesticide and others. In that matter, bamboo charcoal is a potential cheaper alternative absorbent among carbon based material such as carbon nanotubes [18, 19], graphene [19], graphene oxide [19] and others which offers a larger specific area and greater pore volume which can perform a greater degree of adsorption.

It has been shown that, the adsorption of bamboo charcoal is affected by the carbonization temperature as shown in Fig. 4(a). As the temperature increased, the pore is greater and the adsorption rate is increased. The adsorption of substances in water also depends on the way the bamboo charcoal is activated. It has been investigated that bamboo charcoal activated with $\mathrm{HNO}_{3}$ (refer Fig. 4(b)) showed better surface area with the introduction of acidic functional groups without destruction of pore structure compared to the charcoal activated with $\mathrm{CO}_{2}$ (refer Fig. 4(c)) which much depends on the activated temperature [2]. Author also proved that charcoal activated by $\mathrm{NH}_{3}$ not present a promising yield although the mesopore was increased with the applied temperature. However this $\mathrm{HNO}_{3}$ activation process posses more functional groups and resulted higher water vapour adsorption capacity at low humidity area.

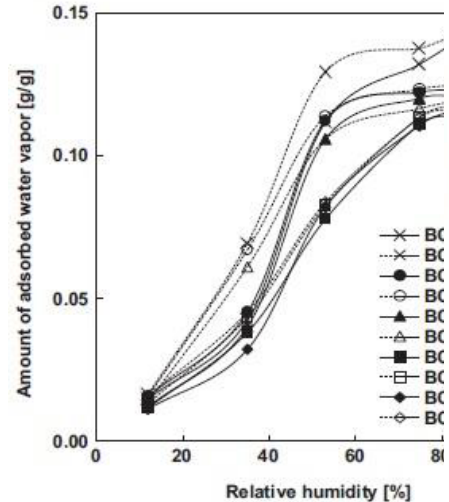

(a)

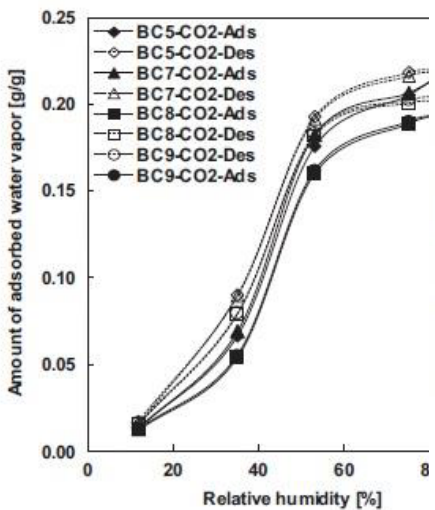

(b)

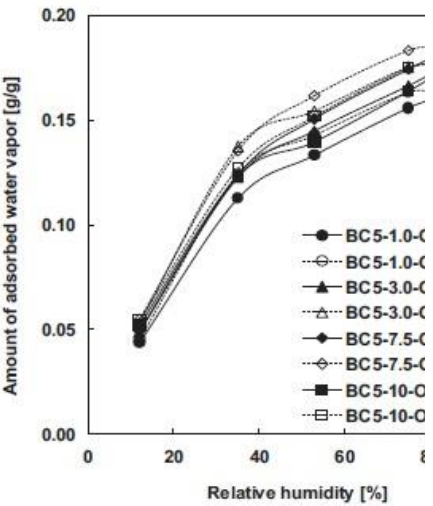

(c)

Fig. 4. Water vapour adsorption-desorption of (a) bamboo charcoal, (b) activated $\mathrm{CO}_{2}$ and (c) activated $\mathrm{HNO}_{3}[2]$.

\section{As an electromagnetic waves absorber}

Due to the extensive effort towards gigahertz (Ghz) electronic system and telecommunication devices, electromagnetic (EM) interference problems have raised vastly. EM is defined as conducted or radiated electromagnetic signals which emitted by 
electrical circuits which under operation, perturb proper operation of surrounding equipments which also may cause radioactive damage to living/biological species [3]. Thus, an effective shielding material in wide variety applications is needed. For this purposes, Radar Adsorbing Material (RAM) has been applied from commercial and electronic instrumentations to antenna system and military electronic devices which can be produced under different forms such as conductive paints or rubber loaded with ferrite or carbon which generally used for stealth military planes; or in foam or multilayered topologies that commonly used as liners for all enclosures in which reflection waves has to be minimized such as an anechoic chambers. But, the existing adsorption solution is still facing very low power loss.

Recently, the focus on the research on designing shielding material which works by adsorption was boosted all over the world. Most of the proposed material was based on polymeric materials in order to take the advantages of their lightness, low cost, easy shaping and others. There are three main strategies on producing the adsorbing material: 1) dispersion of metallic fillers, fibers or nanoparticles within polymer matrix which can increase the interaction with the electromagnetic radiation; 2) using conductive polymers such polyaniline (PANI) and polydimethylsiloxane (PDMS) and 3) dispersion carbon based electrically conductive polymer matrices. Based on that, carbon material like carbon black [20], carbon nanotubes [21] and graphene [22 - 24] have been used as the polymeric filler because of their extraordinary properties. However the production of these carbon materials is expensive and some of the materials are facing impedance match mechanism that may harmful to the EM adsorption properties [24]. Besides, the carbon based dielectric absorbers have narrow absorbing frequency bandwidth [25]. Therefore, a development of the EM absorbing material with low density, high thermal stability, high absorption properties, broad microwave frequency bandwidth as well as cheaper solution is highly demanded. Based on that demands, bamboo charcoal can be a magnificent alternative as this material has similar high conductivity, large surface area and extremely higher adsorption properties.

\section{Conclusion}

In this paper, the properties and potential applications are reviewed. The magnificent adsorption property of this material becomes the main highlight which it can be fully utilized in various potential applications such as electrode in solar cell, absorbent for water treatment and wave absorber in antenna. This adsorption property can be influenced by the carbonization temperature, the activation process and activation precursor as the pore is getting larger and the surface area is improved.

\section{References}

1. C.S. Chou, C.Y. Chen, S.H. Lin, W.H. Lu, P. Wu, Adv. Powder Technol., 26, 711 (2015)

2. R. Wang, Y. Amano, M. Machida, J. Anal. Appl. Pyrol., 104, 667 (2013)

3. J.M. Thomassin, C. Jerome, T. Pardoen, C. Bailly, I. Huynen, C. Detrembleur, Mat. Sci. Eng. R., 74, 211 (2013)

4. Y.S.H. Lin, L.Y. Hsu, C.S. Chou, J.W. Jhang, P. Wu, J. Anal. Appl. Pyrol., 107, 9 (2014)

5. M. Sakuma, Y. Amano, M. Machida, Tanso, 252, 1 (2012)

6. T. Horikawa, Y. Kitakaze, T. Sekida, J. Hayashi, M. Katoh, Bioresource Technol., 101, 3964 (2010) 
7. P. Chingombe, B. Saha, R.J. Wakeman, Carbon, 43, 3132 (2005)

8. R. Okayama, M.A.A. Zaini, M. Aikawa, M. Machida, H. Tatsumoto, J. Environ. Chem., 18, 533 (2008)

9. C.H. Wang, United States Patent Application No. 11/147,371 (2005)

10. http://www.faqs.org/patents/app/20100307066

11. http://www.c60bamboo.com

12. X. Chen, S.S. Mao, Chem. Rev., 107, 2891 (2007)

13. X. Chen, L. Liu, P.Y. Yu, S.S. Mao, Science, 331, 746 (2011)

14. M.R. Hoffmann, S.T. Martin, W. Choi, D.W. Bahnemann, Chem. Rev., 95, 69 (1995)

15. A.C.M.S. Esteban, E.P. Enriquez, Sol. Energy, 98, 392 (2013)

16. Z. Yang, L. Li, H. Lin, Y. Luo, R. He, L. Qiu, J. Ren, H. Peng, Chem. Phys. Lett., (2012)

17. L.H. Chang, C.K. Hsieh, M.C. Hsiao, J.C. Chiang, P.I. Liu, K.K. Ho, C.C.M. Ma, M.Y. Yen, M.C. Tsai, C.H. Tsai, J. Power Sources, 222, 518 (2013)

18. X. Liu, M. Wang, S. Zhang, B. Pan, J. Environ. Sci., 25, 1263 (2013)

19. S.C. Smith, F. Ahmed, K.M. Gutierrez, D.F. Rodrigues, Chem. Eng. J., 240, 147 (2014)

20. S. Vinayasree, M.A. Soloman, V. Sunny, P. Mohanan, P. Kurian, M.R. Anantharaman, Compos. Sci. Technol., 82, 69 (2013)

21. Z. Liu, G. Bai, Y. Huang, F. Li, Y. Ma, T. Guo, X. He, X. Lin, H. Gao, Y. Chen, J. Phys. Chem. C., 111, 13696 (2007)

22. V.K. Singh, A. Shukla, M.K. Patra, L. Saini, R.K. Jani, S.R. Vadera, N. Kumar, Carbon, 50, 2202 (2012)

23. B. Wu, H.M. Tuncer, A. Katsounaros, W. Wu, M.T. Cole, K. Ying, L. Zhang, W.I. Milne, Y. Hao, Carbon, 77, 814 (2014)

24. Y. Chen, Z. Lei, H. Wu, C. Zhu, P. Gao, Q. Ouyang, L.H. Qi, Q. Qin, Mater. Res. Bull., 48, 3362 (2013)

25. J. Zeng, J. Xu, J. Alloy. Compd., 493, 39 (2010) 